\title{
Effects of Gocovri (Amantadine) Extended Release Capsules on Non-Motor Symptoms in Patients with Parkinson's Disease and Dyskinesia
}

\author{
Shyamal H. Mehta · Rajesh Pahwa · Caroline M. Tanner • \\ Robert A. Hauser · Reed Johnson
}

Received: December 30, 2020 / Accepted: March 22, 2021 / Published online: April 17, 2021

(C) The Author(s) 2021

\begin{abstract}
Introduction: Gocovri (amantadine) extended release capsules are approved for treatment of dyskinesia and as a levodopa adjunct for OFF episodes in patients with Parkinson's disease (PD). We report treatment-related effects on non-motor symptoms (NMS) assessed as secondary outcomes in two trials using the Movement Disorder Society-Unified Parkinson's Disease Rating Scale (MDS-UPDRS) Part I.

Methods: EASE LID and EASE LID 3 enrolled levodopa-treated patients with PD and $\geq 1 \mathrm{~h}$ /day ON time with troublesome dyskinesia. Patients were randomized to Gocovri (274 mg) or placebo taken daily at
\end{abstract}

S. H. Mehta $(\bowtie)$

Department of Neurology, Mayo Clinic-Scottsdale, 13400 East Shea Blvd, Scottsdale, AZ 85254, USA e-mail: mehta.shyamal@mayo.edu

R. Pahwa

Department of Neurology, University of Kansas

Medical Center, Kansas City, KS, USA

C. M. Tanner

Department of Neurology, University of California, San Francisco, CA, USA

R. A. Hauser

USF Parkinson's Disease and Movement Disorders Center Parkinson Foundation Center of Excellence, University of South Florida, Tampa, FL, USA

R. Johnson

Adamas Pharmaceuticals, Inc., Emeryville, CA, USA bedtime. Treatment differences from baseline to week 12 in MDS-UPDRS Part I were evaluated for the pooled population $(N=196)$ from both trials. Correlation analyses of NMS (MDSUPDRS Part I) with dyskinesia using Unified Dyskinesia Rating Scale (UDysRS) scores were performed.

Results: For changes in the MDS-UPDRS Part I items, the treatment difference favored Gocovri in daytime sleepiness $(P=0.006)$ and depression $(P=0.049)$ scores, but favored placebo in cognitive impairment $(P=0.038)$, and hallucinations and psychosis $(P<0.001)$ scores. The treatment difference for the changes in total Part I score was -0.8 , favoring Gocovri $(P=0.22)$. At baseline, MDS-UPDRS Part I modestly correlated with UDysRS score $(r+0.25, P<0.001)$, and improvement in NMS correlated with improvement in dyskinesia at week 12 for Gocovri $(r+0.39, P<0.001)$ but not placebo $(r+0.12, P=0.29)$. The most commonly reported adverse events for Gocovri were hallucination (21\%); dizziness, dry mouth, and peripheral edema (16\% each); and constipation, falls, and orthostatic hypotension (13\% each).

Conclusion: This post hoc analysis shows potential benefit with Gocovri treatment for the NMS of daytime sleepiness and depression in dyskinetic PD patients. Overall, improvement in NMS scores correlated with improvement in dyskinesia.

Trial Registration: ClinicalTrials.gov identifiers: NCT02136914 and NCT02274766 
Keywords: Amantadine;

Depressive disorder;

Depression;

Hallucinations; Parkinson's disease; Sleep

\section{Key Summary Points}

\section{Why carry out this study?}

Gocovri (amantadine) extended release is approved for treatment of dyskinesia and OFF episodes in people with Parkinson's disease (PD) receiving levodopa-based therapy.

People with PD experience, in addition to the familiar motor symptoms, non-motor neuropsychiatric symptoms, sleep disturbances, dysautonomias, and sensory abnormalities.

Gocovri-related effects on non-motor symptoms were assessed over 12 weeks using the Movement Disorder Society-Unified Parkinson's Disease Rating Scale (MDS-UPDRS) Part I scores in a post hoc analysis of a pooled population of dyskinetic PD patients from two phase 3 trials.

\section{What was learned from the study?}

Treatment significantly favored Gocovri vs. placebo in daytime sleepiness and depression.

Non-motor symptom improvements correlated with dyskinesia improvement for Gocovri, but not placebo, presenting an interesting avenue for further exploration.

\section{DIGITAL FEATURES}

This article is published with digital features, including a summary slide, to facilitate understanding of the article. To view digital features for this article go to https://doi.org/10.6084/ m9.figshare.14248481.

\section{INTRODUCTION}

Although the motor symptoms of Parkinson's disease (PD) are typically the main focus of management efforts, non-motor symptoms (NMS) occur in almost all patients [1-3]. They have been found at all PD stages [1], often in combination [1, 4], yet clinicians seeking to ameliorate a patient's motor dysfunction may fail to recognize them $[5,6]$ and patients themselves may fail to report them, or may not attribute them to PD [6, 7]. Non-motor symptoms encompass a broad array of complaints, including neuropsychiatric symptoms (e.g., depression, cognitive impairment, hallucinations), sleep disturbances (e.g., rapid eye movement sleep behavior disorder, insomnia, somnolence), dysautonomias (e.g., constipation, nocturia, orthostatic hypotension), and sensory abnormalities (e.g., pain, anosmia) $[2,3,6,8]$. Together, these can have a substantial adverse impact on a patient's quality of life, sometimes exceeding that of the patient's motor symptoms $[2,9]$.

In 2007, the Unified Parkinson's Disease Rating Scale (UPDRS) [10], the gold-standard tool for tracking PD severity, was modified and renamed the Movement Disorder Society-UPDRS (MDS-UPDRS) [11]. The revised scale included, in Part I, a rating scale of non-motor effects on patients' experiences of daily living. Assessment of NMS is an important additional dimension for evaluating the holistic effectiveness of a PD medication.

Gocovri $^{\circledR} \quad$ (amantadine extended release capsules, Adamas Pharmaceuticals, Inc.) is an extended-release, orally administered amantadine formulation approved by the U.S. Food and Drug Administration specifically for treatment of dyskinesia and/or OFF episodes in patients with $\mathrm{PD}$ receiving levodopa-based therapy, with or without concomitant dopaminergic medications [12, 13]. In each of two pivotal phase 3 trials $[14,15]$, Gocovri significantly reduced dyskinesia and OFF time relative to placebo, as measured by the Unified Dyskinesia Rating Scale [16] (UDysRS; primary outcome), PD patient diaries and Part IV of the MDS-UPDRS measuring motor complications 
$[14,15,17]$. Gocovri was designed to produce a slow rise in amantadine plasma concentrations that, when taken at bedtime, approach maximum around morning awakening and are sustained throughout the day, and decrease during evening hours to reduce potential for sleep disruption [13].

We performed a post hoc analysis of these two pivotal phase 3 trials to investigate the effects of Gocovri versus placebo on non-motor PD symptoms using MDS-UPDRS Part I item scores.

\section{METHODS}

\section{Study Designs and Participants}

Methods and primary results of both trials have been published previously. EASE LID [15] (ClinicalTrials.gov identifier: NCT02136914) was an up to 6-month trial comparing Gocovri and placebo in PD patients with dyskinesia taking a stable PD medication regimen with carbidopa/levodopa, alone or with other antiparkinsonian drugs. EASE LID 3 [14] (NCT02274766) was a 3-month study of similar design. In both trials, patients were required to be experiencing at least $1 \mathrm{~h}$ /day (two half-hour periods) of ON time with troublesome dyskinesia between 9 a.m. and 4 p.m., as documented in two consecutive 24 -h diaries $(48 \mathrm{~h}$ total) within 3 days of study entry [18]. In addition, patients were required to report a score of at least 2 on Part IV, item 4.2 (functional impact of dyskinesias) of the MDSUPDRS. In addition, patients were excluded for reasons including orthostatic hypotension, clinically significant hallucinations within 1 year prior to screening, and/or cognitive impairment (Mini-Mental State Examination score $<24$ [19]). Enrolled patients were randomized in a 1:1 ratio to take double-blind Gocovri (137 mg/day for the first week and then $274 \mathrm{mg} /$ day thereafter) or matching placebo once daily at bedtime.

\section{Efficacy Measures}

In EASE LID, MDS-UPDRS scores were obtained at screening, treatment day 1 (baseline) and treatment weeks $2,8,12,18$, and 24 . In EASE LID 3, scores were obtained at screening, baseline, and weeks $1,2,4,8$, and 12 . UDysRS scores and PD home diary measurements were obtained at weeks 0 (baseline), 2, 8, 12, 18 and 24 for EASE LID, and at weeks $0,2,4,8$ and 12 for EASE LID 3. If possible, the same rater conducted all of a patient's assessments, each of which was to take place when the patient was $\mathrm{ON}$ and experiencing their typical dyskinesia and at least 30 min following a patient's regularly scheduled levodopa dose. The primary outcome was the change from baseline to week 12 in the UDysRS total score. For the current analyses, data from the two studies were pooled since, by inspection, the two studies were of similar design and were conducted in the same manner, and the observed changes were similar between the studies. The analyses presented here pertain to weeks 2,8 , and 12 , the assessment time points common to both of the trials and were conducted while patients were receiving $274 \mathrm{mg}$ Gocovri or placebo.

Part I of the MDS-UPDRS (Non-Motor Aspects of Experiences of Daily Living) has two components consisting of a total of 13 items. The first six items (Part IA) are asked of the patient or caregiver by the investigator. The remaining seven items (Part IB) are completed by the patient with or without the aid of the caregiver, but independently of the investigator. All items are anchored with criteria for each response and scored 0 (normal), 1 (slight), 2 (mild), 3 (moderate), or 4 (severe), with reference to the symptom's impact on daily life during the preceding week [20].

Patients completed PD home diaries recording, in 30-min time spans, time spent OFF, ON time with no dyskinesia, ON with non-troublesome dyskinesia, ON with troublesome dyskinesia, and asleep [18]. Diaries were completed for two consecutive 24-h days before each study visit. 


\section{Efficacy Analyses}

In each study, the modified intent to treat (mITT) population consisted of all randomized patients who received at least one study-drug dose and underwent at least one post-baseline UDysRS assessment. Here, mean changes from baseline in MDS-UPDRS Part I total scores and individual item scores were compared between treatment groups in the combined mITT population for the two studies using a mixed model with repeated measurements (MMRM). The model included categorical effects for treatment group, study, visit (weeks 2, 8, and 12) as well as the interaction between treatment group and visit. The baseline value of the MDS-UPDRS Part I total score (or for the individual item, depending on the analyses) was included as a covariate. An unstructured covariance matrix was used to model the within-subject correlation between the repeated visits. If the model did not converge with an unstructured covariance matrix, then a compound symmetry matrix was to be used. The Kenward-Roger approximation was used to estimate the denominator degrees of freedom and to adjust the standard errors. The appropriateness of pooling the studies was assessed by inspection of the results for the individual studies to evaluate their general comparability and the fact that the studies were of similar design (except for the difference in duration) and were conducted in the same manner. Estimates for the least-squares (LS) mean change from baseline at week 12 in each treatment arm, along with the corresponding LS mean treatment difference and $95 \%$ confidence interval (CI) for the difference, were derived from the MMRM model.

Pearson correlation coefficients were calculated to determine the association between MDS-UPDRS Part I scores and UDysRS scores. Correlations were calculated for these measures for all patients at baseline, and for placebo and Gocovri groups at baseline and for change scores at week 12 . The software package SAS (version 9.4; SAS Institute, Cary, NC) was used for analysis.

\section{Safety Measures}

Throughout each study, investigators were responsible for recording all directly observed and patient-reported adverse events (AEs). Each AE was coded according to the Medical Dictionary for Regulatory Activities (MedDRA). Safety data have been previously published for the individual studies and the pooled population.

\section{Ethical Conduct}

Each study was conducted in accordance with the Declaration of Helsinki and with Good Clinical Practice guidelines. Before the start of each study, each study site received approval from an institutional review board, research ethics board, or independent ethics committee, and before any study procedures, written informed consent was obtained from each patient.

\section{RESULTS}

\section{Study Participants}

Patient disposition has been previously reported for each study and for the pooled sample $[14,15,17]$. Across the studies, 303 patients were screened and 203 were randomized (101 to Gocovri and 102 to placebo). The pooled mITT population comprised 196 patients (100 receiving Gocovri and 96 receiving placebo). Among them, 185, 172, and 168 patients provided MDS-UPDRS Part I data at 2, 8, and 12 weeks, respectively $(96,84$, and 82 for Gocovri and 89 , 88 , and 86 for placebo).

Baseline characteristics of the pooled mITT population are presented by treatment group in Table 1. The baseline distribution of MDSUPDRS Part I scores was similar between the two treatment groups, with mean (SD) total scores of 12.1 (6.1) for the Gocovri group and 10.8 (4.4) for the placebo group (Fig. 1). Distribution of item scores across enrolled patients is shown in Fig. 2. Overall, mean scores were higher, indicating greater perceived impairment for the 
Table 1 Patients' baseline characteristics, by treatment group (pooled mITT populations)

\begin{tabular}{|c|c|c|}
\hline Variable & $\begin{array}{l}\text { Gocovri } \\
(N=100)\end{array}$ & $\begin{array}{l}\text { Placebo } \\
(N=96)\end{array}$ \\
\hline Age, mean (SD), years & $64.2(9.5)$ & $65.3(8.8)$ \\
\hline Sex, male, \% & 54.0 & 57.3 \\
\hline Race, White, \% & 96.0 & 92.7 \\
\hline Duration of PD (years), mean (SD) & $9.8(4.7)$ & $9.7(4.1)$ \\
\hline $\begin{array}{l}\text { Duration of levodopa treatment (years), } \\
\text { mean (SD) }\end{array}$ & $7.8(3.9)$ & $7.6(4.1)$ \\
\hline Duration of dyskinesia (years), mean (SD) & $4.0(3.1)$ & $3.6(2.5)$ \\
\hline OFF time $(\mathrm{h} / \mathrm{d})$, mean $(\mathrm{SD})$ & $3.0(2.3)$ & $2.6(2.0)$ \\
\hline MDS-UPDRS Part I total score, mean (SD) & $12.1(6.1)$ & $10.8(4.4)^{\mathrm{a}}$ \\
\hline 1.1: Cognitive impairment & $0.6(0.8)$ & $0.6(0.8)$ \\
\hline 1.2: Hallucinations and psychosis & $0.1(0.3)$ & $0.1(0.3)^{\mathrm{a}}$ \\
\hline 1.3: Depressed mood & $0.6(0.8)$ & $0.4(0.6)^{\mathrm{a}}$ \\
\hline 1.4: Anxious mood & $0.8(0.8)$ & $0.6(0.6)$ \\
\hline 1.5: Apathy & $0.5(0.8)$ & $0.4(0.8)$ \\
\hline 1.6: Dopamine dysregulation syndrome & $0.1(0.4)$ & $0.1(0.5)$ \\
\hline 1.7: Sleep problems & $1.8(1.2)$ & $1.6(1.2)$ \\
\hline 1.8: Daytime sleepiness & $1.5(0.9)$ & $1.4(0.9)$ \\
\hline 1.9: Pain and other sensations & $1.6(1.1)$ & $1.4(1.1)$ \\
\hline 1.10: Urinary problems & $1.1(1.2)$ & $1.0(1.0)$ \\
\hline 1.11: Constipation problems & $1.0(0.9)$ & $0.9(0.9)$ \\
\hline 1.12: Lightheadedness on standing & $0.9(1.0)$ & $0.7(0.8)$ \\
\hline 1.13: Fatigue & $1.5(1.0)$ & $1.4(0.9)$ \\
\hline MDS-UPDRS Part II Total Score, mean (SD) & $15.1(6.6)$ & $15.3(5.9)$ \\
\hline MDS-UPDRS Part III Total Score, mean (SD) & $24.2(13.0)$ & $23.4(11.5)$ \\
\hline MDS-UPDRS Part IV Total Score, mean (SD) & $11.1(3.0)$ & $11.2(2.4)$ \\
\hline
\end{tabular}

MDS-UPDRS Movement Disorder Society Unified Parkinson's Disease Rating Scale, $m I T T$ modified intent-to-treat, $P D$ Parkinson's disease, $S D$ standard deviation

${ }^{\mathrm{a}} n=95$

patient-rated symptoms (items 7-13) than for the investigator-rated symptoms (items 1-6), with $49-87 \%$ scoring at least mild on patientrated items compared with $0-12 \%$ on investigator-rated items. Lower scores on some Part IA
NMS such as orthostatic hypotension, hallucinations, and cognition were expected, since these overlapped with trial exclusion criteria. The NMS for which the most patients reported scores of $\geq 2.0$ (mild or greater impact) at 


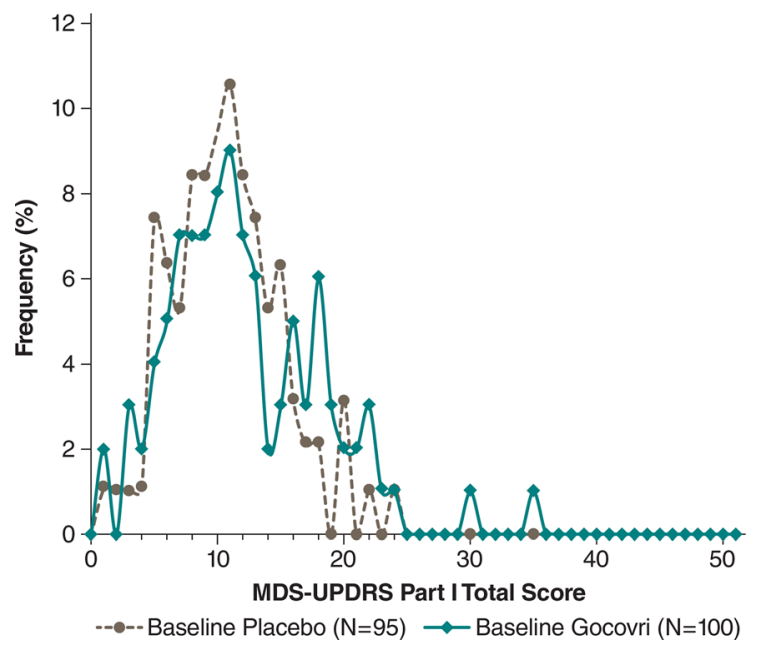

Fig. 1 MDS-UPDRS Part I total score distribution at baseline by treatment group. Frequency based on percentage of patients in group. Highest possible Total score is 52 (13 items $\times 4$ points $\max$ per item)

baseline were sleep problems (insomnia, falling or staying asleep) (58\% of patients), daytime sleepiness (55\%), pain (44\%), and fatigue (43\%).

\section{Treatment Effects on Non-Motor Symptoms}

The time course of least-squares (LS) mean change from baseline in MDS-UPDRS Part I total score for each pooled treatment group is displayed in Fig. 3. The treatment difference was largest at week 12, where the MDS-UPDRS Part I total score LS mean (SE) treatment difference was $-0.8(0.6)$, favoring Gocovri numerically over placebo, but was not significant $(P=0.221)$. With respect to the clinical significance of changes, Horvath and colleagues, in an analysis of 365 patients, considered minimal clinically important differences (MCID) to be a $>2.64$-point improvement or a $>2.45$-point worsening of the MDS-UPDRS Part I score [21]. In this respect, more patients treated with Gocovri showed an MCID improvement $(\geq 3$ points) than with placebo $(42.7 \%$ vs. $31.4 \%)$ and fewer Gocovri-treated patients showed MCID declines than placebo-treated patients (12.2\% vs. $18.6 \%)$ (Table 2 ).

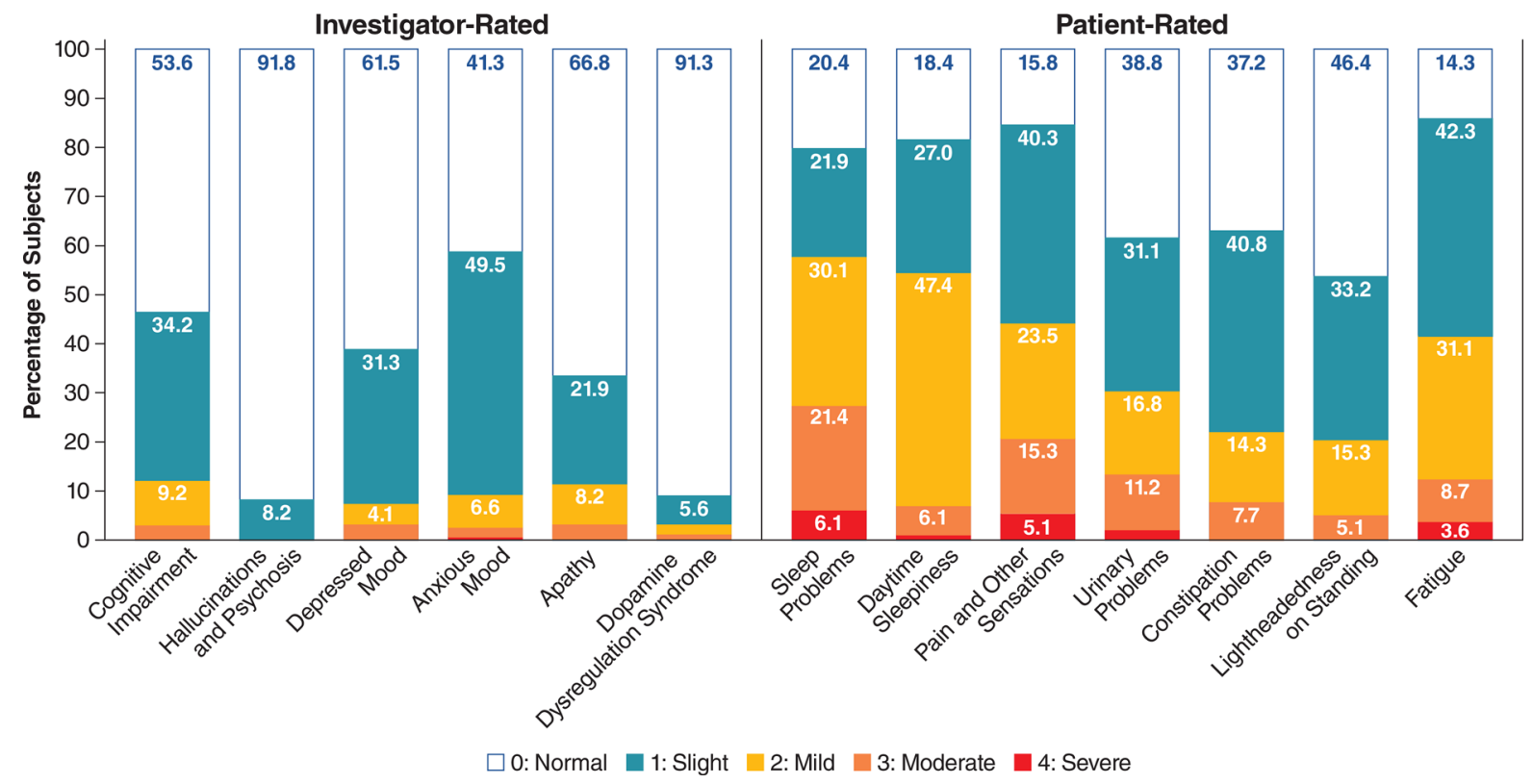

Fig. 2 Distribution of MDS-UPDRS Part I item scores for all patients at baseline. Note that "investigator rated" items are assessed by the investigator with all pertinent information from patients and caregivers. Values for labels not shown in the figure: Cognitive impairment: moderate, 3.1\%. Depressed mood: moderate, 3.1\%. Anxious mood: moderate, $2.0 \%$; severe, $0.5 \%$. Apathy: moderate, $3.1 \%$. Dopamine dysregulation syndrome: mild, $2.0 \%$; moderate, 1.0\%. Daytime sleepiness: severe, $1.0 \%$. Urinary problems: severe, $2.0 \%$ 


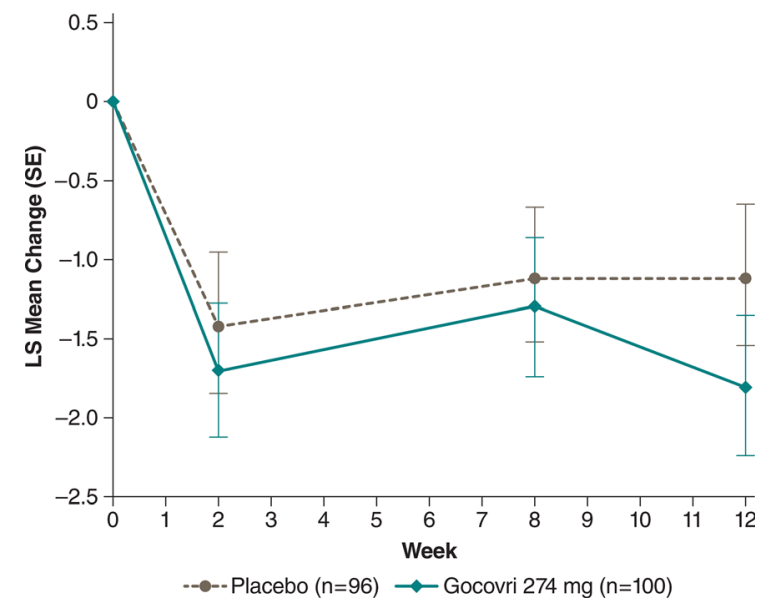

Fig. 3 Time course of LS mean change from baseline in MDS-UPDRS Part I total score for all patients. LS, leastsquares; MDS-UPDRS, Movement Disorder Society Unified Parkinson's Disease Rating Scale

For each of the MDS-UPDRS Part I items, Fig. 4 displays the LS mean placebo-subtracted treatment difference from baseline to week 12 . Gocovri-related reduction in MDS-UPDRS Part I total score was driven primarily by statistically significant improvement in self-rated daytime sleepiness (LS mean treatment difference, -0.3 ; $P=0.006)$ and investigator-rated depression $(-0.2 ; P=0.049)$. There was a trend towards improvement in self-rated pain in the Gocovri group $(-0.3$ but this did not reach significance $(P=0.075)$. Conversely, Gocovri showed an increase relative to placebo for 2 of the 13 items: investigator-rated hallucinations/psychosis (LS mean treatment difference, $+0.2 ; \quad P<0.001$ ) and investigator-rated cognitive impairment $(+0.2 ; \quad P=0.038)$. The overall percentage of patients with improvement or decline on each MDS-UPDRS Part I item are shown in Table 2.

\section{Correlation of Non-Motor Symptoms with Dyskinesia}

Correlation analysis was conducted for MDSUPDRS Part I with UDysRS (the primary outcome measure in phase 3 studies) to further explore the relationship between NMS and dyskinesia. A modest but significant positive overall group correlation was seen at baseline $(r+0.25, \quad P<0.0004)$ (Fig. 5a). At week 12, improvement in NMS was more strongly correlated with improvement in dyskinesia for the Gocovri group $(r+0.39, P<0.001$, but not for the placebo group $(r+0.12, P=0.29)$ (Fig. $5 b)$.

\section{Safety}

AE incidence patterns during EASE LID and EASE LID 3 have been previously published $[14,15,17]$. The most commonly reported AEs ( $\geq 10 \%$ incidence) for Gocovri were hallucination [visual or auditory, 21 out of 100 patients in the safety population (21\%)], dizziness, dry mouth, and peripheral edema (16\% each), and constipation, falls, and orthostatic hypotension (13\% each) [17]. The majority of AEs appeared transient and mild or moderate in intensity. Reported hallucinations were primarily visual (overall incidence 18\%) and were more common in patients aged $\geq 65$ years $(30.8 \%)$ vs. $<65$ years $(10.4 \%)$. Seven patients with visual hallucinations discontinued treatment, three had a dose interruption or reduction, and eight continued treatment; the hallucinations in five of these eight patients resolved prior to end of study. No patient required antipsychotic medications. Cognitive impairment is not a MedDRA preferred term; however confusional state was reported by $3 \%$ of ADS-5102-treated patients in phase 3 studies vs. $2 \%$ for placebo. Other potentially related preferred terms such as cognitive disorder (1\% vs. $0 \%)$, and mental status changes ( $1 \%$ vs. $1 \%)$ were not commonly reported.

\section{DISCUSSION}

MDS-UPDRS Part I scores obtained at baseline suggest the presence of a broad range of concurrent non-motor PD symptoms in these patients with troublesome dyskinesia, with 40\% or more of the patient sample reporting sleep problems, daytime sleepiness, pain, and fatigue that were of sufficient severity to cause difficulties in daily living or social activities. Although few patients $(<15 \%)$ had problems of mild or greater severity at baseline on the cognitive impairment, hallucinations/psychosis, 
Table 2 Change distribution of MDS-UPDRS Part I by treatment group at week 12

\begin{tabular}{|c|c|c|c|}
\hline \multicolumn{2}{|c|}{$\begin{array}{l}\text { Change distribution of MDS-UPDRS Part I by treatment group at week } \\
12\end{array}$} & \multirow{2}{*}{$\begin{array}{l}\text { Any improvement \% subjects } \\
72.0 \%\end{array}$} & \multirow{2}{*}{$\begin{array}{l}\text { Any decline \% subjects } \\
25.6 \%\end{array}$} \\
\hline Overall & Gocovri & & \\
\hline & Placebo & $54.7 \%$ & $38.4 \%$ \\
\hline \multirow[t]{2}{*}{ MCID ( $\geq 3$ points) } & Gocovri & $42.7 \%$ & $12.2 \%$ \\
\hline & Placebo & $31.4 \%$ & $18.6 \%$ \\
\hline \multicolumn{4}{|l|}{ Item scores } \\
\hline \multirow[t]{2}{*}{ Cognitive impairment* } & Gocovri & $23.1 \%$ & $19.5 \%$ \\
\hline & Placebo & $27.6 \%$ & $10.3 \%$ \\
\hline \multirow[t]{2}{*}{ Hallucination/Psychosis* } & Gocovri & $1.2 \%$ & $13.4 \%$ \\
\hline & Placebo & $7.0 \%$ & $1.1 \%$ \\
\hline \multirow[t]{2}{*}{ Depressed mood* } & Gocovri & $29.3 \%$ & $13.4 \%$ \\
\hline & Placebo & $18.6 \%$ & $22.1 \%$ \\
\hline \multirow[t]{2}{*}{ Anxious mood } & Gocovri & $26.8 \%$ & $19.5 \%$ \\
\hline & Placebo & $21.8 \%$ & $23.0 \%$ \\
\hline \multirow[t]{2}{*}{ Apathy } & Gocovri & $22.0 \%$ & $9.8 \%$ \\
\hline & Placebo & $19.5 \%$ & $13.8 \%$ \\
\hline \multirow[t]{2}{*}{ Dopamine dysregulation syndrome } & Gocovri & $7.3 \%$ & $3.7 \%$ \\
\hline & Placebo & $4.6 \%$ & $5.7 \%$ \\
\hline \multirow[t]{2}{*}{ Sleep problems } & Gocovri & $47.6 \%$ & $22.0 \%$ \\
\hline & Placebo & $35.6 \%$ & $19.5 \%$ \\
\hline \multirow[t]{2}{*}{ Daytime sleepiness* } & Gocovri & $34.1 \%$ & $12.2 \%$ \\
\hline & Placebo & $23.0 \%$ & $18.4 \%$ \\
\hline \multirow[t]{2}{*}{ Pain } & Gocovri & $56.1 \%$ & $9.8 \%$ \\
\hline & Placebo & $33.3 \%$ & $26.4 \%$ \\
\hline \multirow[t]{2}{*}{ Urinary } & Gocovri & $29.3 \%$ & $22.0 \%$ \\
\hline & Placebo & $23.0 \%$ & $18.4 \%$ \\
\hline \multirow[t]{2}{*}{ Constipation } & Gocovri & $26.8 \%$ & $18.3 \%$ \\
\hline & Placebo & $21.7 \%$ & $18.4 \%$ \\
\hline \multirow[t]{2}{*}{ Lightheadedness } & Gocovri & $24.4 \%$ & $15.9 \%$ \\
\hline & Placebo & $21.8 \%$ & $19.5 \%$ \\
\hline \multirow[t]{2}{*}{ Fatigue } & Gocovri & $35.4 \%$ & $13.4 \%$ \\
\hline & Placebo & $32.2 \%$ & $23.0 \%$ \\
\hline
\end{tabular}

*Indicates significant treatment difference vs placebo

MCID minimal important clinical difference, MDS-UPDRS Movement Disorder Society Unified Parkinson's Disease Rating Scale

and depressed mood items, these would have been constrained by trial exclusion criteria.

Reported MCIDs for Part I of the MDSUPDRS are an improvement of $>2.64$ points or a decline $>2.45$ points [21]. Using a threshold $\geq 3$ points for individual patient scores, more patients taking Gocovri (42.7\%) than placebo (31.4\%) experienced a meaningful improvement in NMS and fewer experienced a meaningful decline (12.2\% Gocovri and $18.6 \%$ 


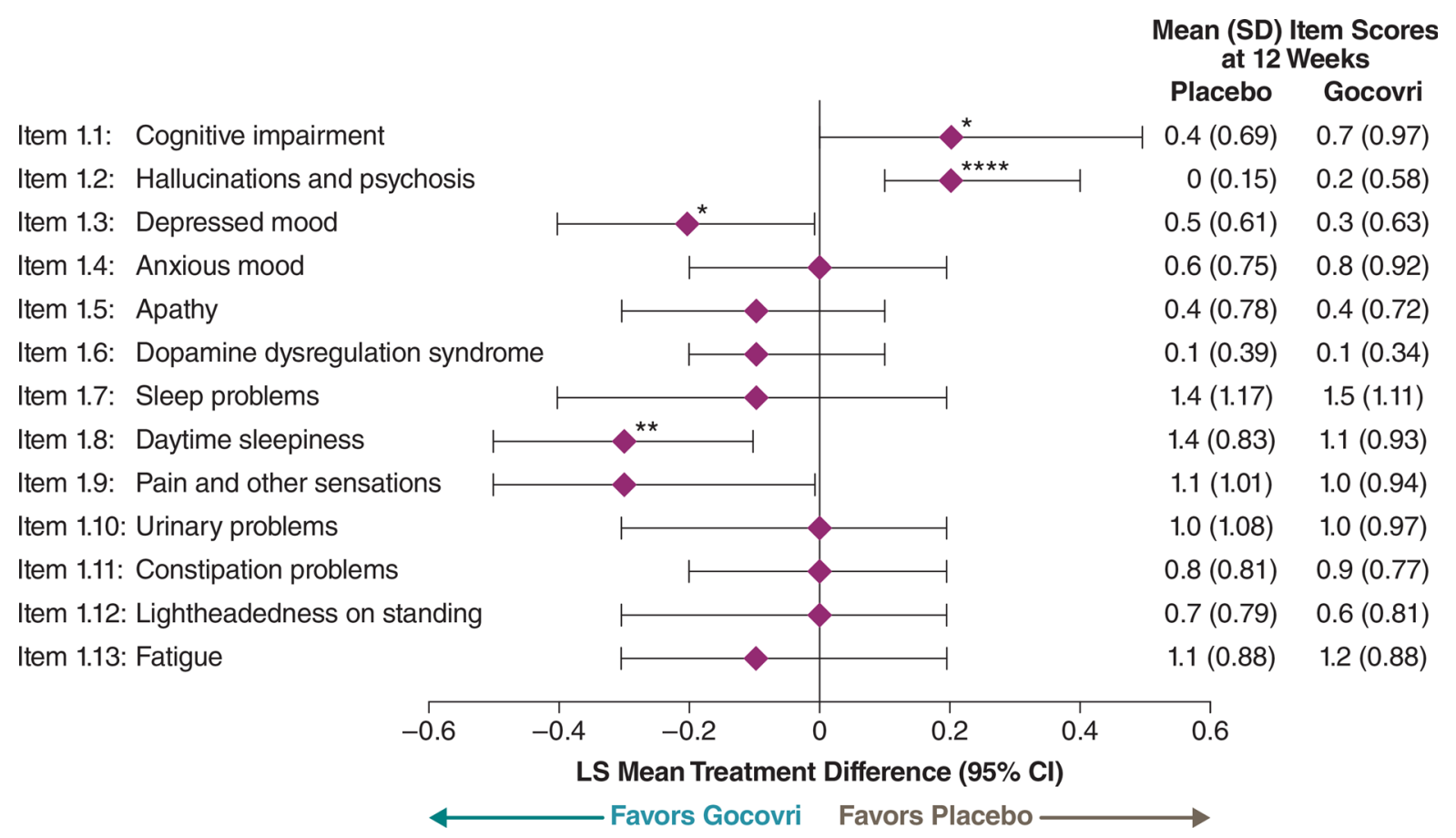

Fig. 4 MDS-UPDRS Part I item scores at week 12: LS mean treatment differences. ${ }^{*} P<0.05,{ }^{* *} P<0.01$, ${ }^{* * *} P<0.0001$ from the MMRM. CI confidence interval,

placebo). Still, the overall week 12 Gocovri-related treatment-difference relative to placebo in MDS-UPDRS Part I $(-0.8)$ did not reach statistical significance relative to placebo $(P=0.22)$, perhaps owing to offsetting effects of opposite directional change for some scale items, combined with the fact that meaningful presence of NMS was not a requirement for study entry, thereby limiting the ability to fully evaluate potential for change in many symptoms.

On item analysis, daytime sleepiness and depression showed significant improvement relative to placebo at 12 weeks, and pain showed a positive trend but did not reach significance. The improvement in daytime sleepiness is particularly interesting, in that the known ability of amantadine to promote wakefulness and cause insomnia factored into the Gocovri product design. The dosage form does not have an immediate-release component and is designed to provide lowest amantadine concentrations in the hours after bedtime administration when patients are trying to sleep, with higher concentrations in the
$L S$, least-squares, MDS-UPDRS Movement Disorder Society Unified Parkinson's Disease Rating Scale

morning and sustained throughout the waking day. The favorable improvement in pain rating is also noteworthy in that a relationship between pain and dyskinesia has been observed in some clinical studies [22], although inconsistent results have been seen in other studies [23], and NMDA receptor antagonists have been associated with modest pain relief in nonclinical pain studies [24]. The significant improvement in the depressed mood item is somewhat surprising in that the low presence of this symptom at baseline combined with the fact that patients with clinical depression were excluded from participation meant that participants had little room to demonstrate substantial improvement; the significant result may have been due in part to more patients showing worsening of depression relative to improvement in the placebo group (22.1\% vs. $18.6 \%)$, whereas the opposite effect was seen with the Gocovri group where more patients showed improvement relative to worsening $(29.3 \% \mathrm{vs}$. 13.4\%). Simuni et al. published a longitudinal analysis of the profile of MDS-UPDRS Part I 


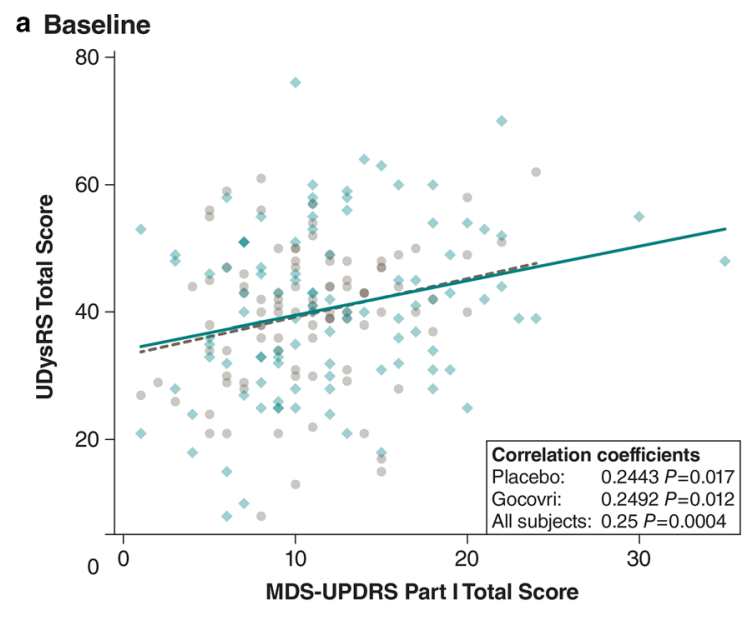

b Change From Baseline to Week 12

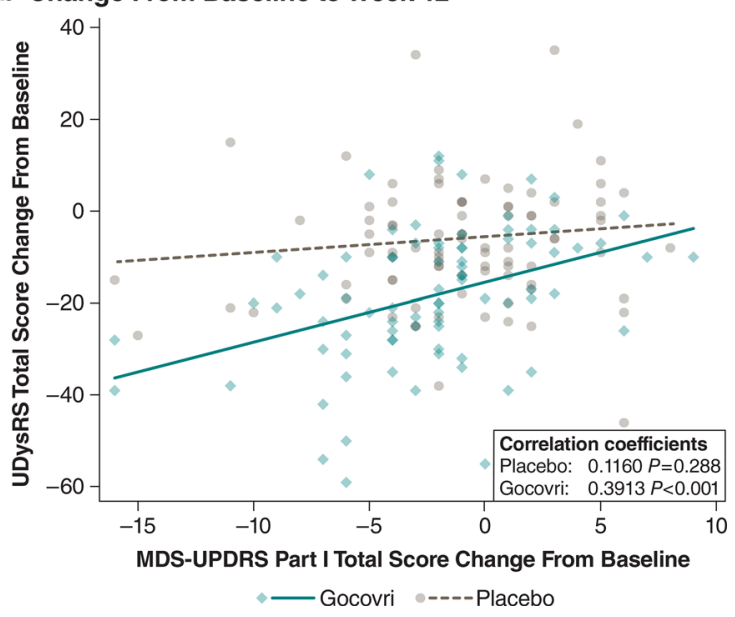

Fig. 5 Correlation between MDS-UPDRS Part I and UDysRS scores. Regression plots for MDS-UPDRS Part I vs. UDysRS total scores are shown at (a) baseline and (b) change from baseline to week 12. MDS-UPDRS, Movement Disorder Society Unified Parkinson's Disease Rating Scale. UDysRS, Unified Dyskinesia Rating Scale (UDysRS)

scores in 423 de novo PD patients from the Parkinson's Progression Markers Initiative cohort [25]. NMS showed significant worsening over a 2-year longitudinal follow-up. Although MDS UPDRS Part I overall and item scores were lower in these early PD patients than in our study (total mean [SD] 5.6 [4.1] at baseline and 7.7 [5.0] at year $2, P<0.001$ ), the profile of NMS symptom presence in this cohort was largely similar to our population with highest scores for Part IB items and lower scores for Part IA.
Several of the commonly reported AEs with Gocovri are also commonly reported NMS in PD, namely, hallucinations, constipation and orthostatic hypotension, and amantadine has also been reported to have anticholinergic-like properties, which in addition to constipation, may additionally lead to concerns for exacerbation of urinary and cognitive NMS [17]. Of these symptoms, only the hallucinations/psychosis and cognitive impairment items showed a negative overall treatment effect for Gocovri, and this treatment difference was also significant relative to placebo. An evaluation of responses on these items showed that these differences may have been due to worsening in a subset of patients. For the cognition item, with Gocovri, 9.8\% worsened by one point, $8.5 \%$ worsened by two points, and $1.2 \%$ worsened by three points (vs. 6.9\%, 3.4\% and $0 \%$ for placebo); whereas for the hallucinations item, with Gocovri, $11.0 \%$ worsened by one point, $1.2 \%$ worsened by two points, and $1.2 \%$ worsened by three points (vs. $1.2 \%$ worsening by one point with placebo) (Table 2).

NMS commonly occur early in PD, increase over time, are often unresponsive to levodopa treatment, and can be difficult to manage. The correlation between NMS (MDS-UPDRS Part I score) and dyskinesia severity (UDysRS score) observed at baseline in our study is consistent with a recently published study by Santos-Garcia et al., which showed a relationship between NMS burden and presence of motor complications (including dyskinesia) in both early and advanced PD [26]. Evaluating 690 PD patients from the COPPADIS cohort, Non-Motor Symptoms Scale (NMSS) total scores were significantly higher in patients with motor complications, including dyskinesia, compared with those with no motor complications. NMS scores showed a moderate correlation with UPDRS Part IV scores $(r+0.45 ; P<0.0001)$. Patients with dyskinesia showed higher NMSS scores than patients without motor complication for all NMSS domains except cardiovascular symptoms, with highest scores for sleep/fatigue and urinary symptom domains). The correlation between improvement in NMS and improvement in dyskinesia in the Gocovri group suggests that effective treatment of 
dyskinesia may have a positive effect on certain NMS.

Limitations of this analysis include firstly that it is a post hoc analysis of a pooled population and there was a lack of statistical adjustment for multiple comparisons. EASE LID and EASE LID 3 were designed to evaluate the effect of Gocovri on dyskinesias as measured using the UDysRS. NMSs at baseline were not required for study admission. Therefore, sensitivity to detect treatment differences in MDS-UPDRS Part I or its components would be expected to be lessened (i.e. low power) by virtue of the characteristics of enrolled subjects. In addition, the trial excluded patients with a history of hallucinations/psychosis, major depression or clinically relevant orthostasis symptoms, which may limit the ability to determine Gocovri clinical effects on these NMS and limit the generalizability of this NMS profile to the broader population of patients with dyskinesia. A key strength of this paper is the requirement that patients have at least $1 \mathrm{~h}$ per day of troublesome dyskinesia (per PD home diary entries) of at least mild impact on activities (per MDS-UPDRS item 4.2), making this one of the few studies to provide data on NMS among a specifically dyskinetic PD population. The MDS-UPDRS Part I scale, although validated and frequently used, is not wholly sufficient to measure and understand the impact of Gocovri on NMS. A more comprehensive measurement of NMS was not included in the pivotal trials of Gocovri, and the use of other specific non-motor instruments, such as the NMSS or the NMS questionnaire, might provide additional useful data. Further studies that assess Gocovri's impact on nonmotor symptoms are warranted.

\section{CONCLUSIONS}

The results of this post hoc analysis suggest that in addition to significant improvements in dyskinesia and OFF time with Gocovri, trial participants experienced improvement in certain NMS as well, including depressed mood and daytime sleepiness. Considering the observed relationship between motor complications and NMS, the correlation between improvement in dyskinesia and improvement in certain NMS with Gocovri presents an interesting avenue for further exploration.

\section{ACKNOWLEDGEMENTS}

We acknowledge and thank the study participants and the EASE LID and EASE LID 3 study investigators and their staff.

Funding. Sponsorship for this study and the journal's Rapid Service Fee were funded by Adamas Pharmaceutical, Inc.

Editorial and Other Assistance. Andrea Formella and Dustin Chernick provided editorial support and assisted with data analysis and interpretation; Andrea Formella is an employee and owns stock in Adamas Pharmaceuticals, Inc., and Dustin Chernick was an employee and owned stock in Adamas Pharmaceuticals, Inc. at the time of manuscript completion. Rob Howard provided statistical analysis programming for this manuscript as a consultant for Adamas Pharmaceuticals, Inc. Lily Llorens provided statistical advice for the analysis as a consultant for Adamas Pharmaceuticals, Inc. Kristi Whitfield generated artwork and figures as a consultant for Adamas Pharmaceuticals, Inc. Editorial support was provided by Robin Smith, PhD of The Curry Rockefeller Group, LLC, which was funded by Adamas Pharmaceuticals.

Authorship. All named authors meet the International Committee of Medical Journal Editors criteria for authorship for this article, take responsibility for the integrity of the work as a whole, and have given their approval for this version to be published.

Authors' Contributions. (1) Research project: A. Conception, All authors. B. Organization, All authors. C. Execution; All authors. (2) Statistical Analysis: A. Design, Reed Johnson and Lily Llorens (acknowledged). B. Execution, Reed Johnson, Rob Howard and Lily Llorens (acknowledged); Coordinated by Reed Johnson and Andrea Formella (acknowledged). 
C. Review and Critique: All authors. (3) Manuscript: A. Writing of first draft, Shyamal Mehta and Robin Smith (acknowledged). B. Review and critique of the manuscript. All authors and Lily Llorens, Andrea Formella, and Dustin Chernick (acknowledged). C. Approval of final draft for submission: All authors.

Disclosures. Shyamal H. Mehta serves as a consultant for Adamas Pharmaceuticals, who funded this research. He consults for CNS Ratings, Adamas Pharmaceuticals, Abbott, and received grants from Arizona Biomedical Research Commission (ABRC) Grant ADHS 16-162,411, International Essential Tremor Foundation (IETF) Grant, Eli Lilly, Pharma2B and Neuraly. Rajesh Pahwa received consulting fees from Abbott, AbbVie, ACADIA, Acorda, Adamas, Cala Health, Global Kinetics, Impel Neuropharma, Lundbeck, Neurocrine, Orbis Bioscience, PhotoPharmics, Prilenia, Sunovion, Teva Neuroscience, US World Meds. He also received research support from Abbott, AbbVie, Acorda, Biogen, Boston Scientific, Cala Health, Cavion, Cynapsus, Intec, Kyowa, Lilly, NIH/ NINDS, NPF, PSG, Roche, Sunovion, Theranexus, Theravance, US WorldMeds Voyager. Caroline Tanner is an employee of the University of California-San Francisco, and the San Francisco Veterans Affairs Health Care System. She receives grants from the Michael J. Fox Foundation, the Parkinson's Foundation, the Department of Defense, BioElectron, Roche/ Genentech, Biogen Idec, and the National Institutes of Health; compensation for serving on data monitoring committees from Voyager Therapeutics, Intec Pharma, and Cadent Therapeutics; and personal fees for consulting from Neurocrine Biosciences, Adamas Therapeutics, Grey Matter, Acorda Therapeutics, Acadia, Amneal, and CNS Ratings. Robert A. Hauser received consulting fees from AbbVie, Acadia Pharmaceuticals, Acorda Therapeutics, Adamas Pharmaceuticals, Affiris, Alliance for Ageing Research, AlphaSights, Amneal Pharmaceuticals, Apopharma, Aptis Partners LLC, Aranca, Axovant, Britannia, Cadent, CAVR, Cerespir, ClearView, Clinical SCORE LLC, CNS Ratings LLC, Compass Group, Decision Resource Group, Dedham Group, Defined Health, Denali,
Enterin, Ernest and Young S.L., Extera, Gerson Lehman Group Inc., Global Kinetic Consulting, Guidepoint Global, Health Advances, Huron, Impax Laboratories, Impel Neuropharma, Inhibikase, InSearch Consulting, Insignia Strategies, International Stem Cell Corporation, Intrace, IQVIA, Jazz Pharmaceuticals, Kaiser, Kashiv Pharma, KeiferRX, KeyQuest, KX Advisors, Kyowa Kirin Pharmaceuticals, L.E.K Consulting, Lundbeck A/S, Medscape, MediTech, Michael J Fox Foundation, Movement Disorder Society, MPTA, NeuroChallenge Foundation for PD, Neurocrine Biosciences Inc., Neuroderm, NOVUS, Orion, Parkinson's Foundation, Parkinson's Study group, Penn Technology Partnership, Pennside partners, Perception OpCo (CEREVEL Therapeutics), Prescott Medical Group, Regenera Pharma, ROCHE (F. Hoffmann Ltd.), Schlesinger Associates, Scion Neurostim, Seelos Therapeutics, Slingshot Insights, Sunovion Pharmaceuticals Inc, TEVA Pharmaceuticals, The Lockwood Group, Tolmar Inc, US World Meds. Dr. Hauser participated in company sponsored speaker bureaus for Acorda Therapeutics, Adamas Pharmaceuticals, Amneal Pharmaceuticals Inc., Kyowa Kirin Pharmaceutical Development, Neurocrine Biosciences and US WorldMeds. Dr. Hauser has received research support from AbbVie Inc, Acorda Therapeutics, AstraZeneca, Axovant Sciences, Biogen Inc, Cavion, Centogene, Cerevance, Cerevel, Covance, Enterin Inc, Global Kinetics Corp., Impax Laboratories LLC, Intec Pharma Ltd, Jazz Pharmaceuticals, NeuroDerm, Lundbeck, Michael J Fox Foundation for Parkinson's Research, Neuraly, Pharma2B, F. Hoffman-La Roche, Revance Therapeutics Inc, Sanofi-Genzyme, and Sunovion Pharmaceuticals. Dr. Hauser received grant support from: Parkinson's Foundation. Dr. Hauser has stock option ownership in: Axial Biotherapeutics, Inhibikase Therapeutics Inc. Reed Johnson is an employee of, and owns stock in, Adamas Pharmaceuticals.

Compliance with Ethics Guidelines. The original studies received approval from all institutions and ethics committees as specified in the original study publications $[14,15,17]$. The studies were performed in accordance with the Helsinki Declaration of 1964, and its later 
amendments. All subjects provided informed consent to participate in the studies.

Data Availability. Where patient data can be anonymized, Adamas Pharmaceuticals Inc will share all individual participant data that underlie the results reported in this article with qualified researchers who provides valid research questions. Study documents, such as the study protocol and clinical study report, are not always available. Requests to access the datasets should be directed to info@adamaspharma.com.

Open Access. This article is licensed under a Creative Commons Attribution-NonCommercial 4.0 International License, which permits any non-commercial use, sharing, adaptation, distribution and reproduction in any medium or format, as long as you give appropriate credit to the original author(s) and the source, provide a link to the Creative Commons licence, and indicate if changes were made. The images or other third party material in this article are included in the article's Creative Commons licence, unless indicated otherwise in a credit line to the material. If material is not included in the article's Creative Commons licence and your intended use is not permitted by statutory regulation or exceeds the permitted use, you will need to obtain permission directly from the copyright holder. To view a copy of this licence, visit http://creativecommons.org/licenses/by$\mathrm{nc} / 4.0 /$.

\section{REFERENCES}

1. Barone $\mathrm{P}$, Antonini A, Colosimo C, Marconi R, Morgante L, Avarello TP, et al. The PRIAMO study: a multicenter assessment of nonmotor symptoms and their impact on quality of life in Parkinson's disease. Mov Disord. 2009;24(11):1641-9. https:// doi.org/10.1002/mds.22643.

2. Chaudhuri KR, Odin P, Antonini A, Martinez-Martin P. Parkinson's disease: the non-motor issues. Parkinsonism Relat Disord. 2011;17(10):717-23. https://doi.org/10.1016/j.parkreldis.2011.02.018.

3. Weerkamp NJ, Tissingh G, Poels PJ, Zuidema SU, Munneke M, Koopmans RT, et al. Nonmotor symptoms in nursing home residents with Parkinson's disease: prevalence and effect on quality of life. J Am Geriatr Soc. 2013;61(10):1714-21. https:// doi.org/10.1111/jgs.12458.

4. Chaudhuri KR, Martinez-Martin P, Schapira AH, Stocchi $\mathrm{F}$, Sethi $\mathrm{K}$, Odin $\mathrm{P}$, et al. International multicenter pilot study of the first comprehensive self-completed nonmotor symptoms questionnaire for Parkinson's disease: the NMSQuest study. Mov Disord. 2006;21(7):916-23. https://doi.org/10. 1002/mds.20844.

5. Shulman LM, Taback RL, Rabinstein AA, Weiner WJ. Non-recognition of depression and other nonmotor symptoms in Parkinson's disease. Parkinsonism Relat Disord. 2002;8(3):193-7.

6. Gallagher DA, Lees AJ, Schrag A. What are the most important nonmotor symptoms in patients with Parkinson's disease and are we missing them? Mov Disord. 2010;25(15):2493-500. https://doi.org/10. $1002 /$ mds.23394.

7. Chaudhuri KR, Prieto-Jurcynska C, Naidu Y, Mitra T, Frades-Payo B, Tluk S, et al. The nondeclaration of nonmotor symptoms of Parkinson's disease to health care professionals: an international study using the nonmotor symptoms questionnaire. Mov Disord. 2010;25(6):704-9. https://doi.org/10.1002/ mds. 22868 .

8. Zesiewicz TA, Sullivan KL, Arnulf I, Chaudhuri KR, Morgan JC, Gronseth GS, et al. Practice Parameter: treatment of nonmotor symptoms of Parkinson disease: report of the Quality Standards Subcommittee of the American Academy of Neurology Neurology. 2010;74(11):924-31. https://doi.org/10. 1212/WNL.0b013e3181d55f24.

9. Schrag A, Jahanshahi M, Quinn N. What contributes to quality of life in patients with Parkinson's disease? J Neurol Neurosurg Psychiatry. 2000;69(3):308-12.

10. Fahn S, Elton R (1987) Members of the UPDRS Development Committee. Unified Parkinson's Disease Rating Scale. In: Fahn S, Marsden C, Calne D, Goldstein M, editors. Recent Developments in Parkinson's Disease, Vol 2. Florham Park, NJ: Macmillan Health Care Information. Pp 153-63, 293-304.

11. Goetz CG, Tilley BC, Shaftman SR, Stebbins GT, Fahn S, Martinez-Martin P, et al. Movement Disorder Society-sponsored revision of the Unified Parkinson's Disease Rating Scale (MDS-UPDRS): scale presentation and clinimetric testing results. Mov Disord. 2008;23(15):2129-70. https://doi.org/ $10.1002 /$ mds.22340. 
12. GOCOVRI (amantadine) extended release capsules for oral use (prescribing information) Emeryville, CA. 2017: Adamas Pharma, LLC; 2021. https:// www.gocovrihcp.com/pdf/Gocovri_Prescribing Information.pdf.

13. Hauser RA, Pahwa R, Wargin WA, Souza-Prien CJ, McClure N, Johnson R, et al. Pharmacokinetics of ADS-5102 (amantadine) extended release capsules administered once daily at bedtime for the treatment of dyskinesia. Clin Pharmacokinet. 2019;58(1):77-88. https://doi.org/10.1007/s40262018-0663-4.

14. Oertel W, Eggert K, Pahwa R, Tanner CM, Hauser RA, Trenkwalder C, et al. Randomized, placebocontrolled trial of ADS-5102 (amantadine) extended-release capsules for levodopa-induced dyskinesia in Parkinson's disease (EASE LID 3). Mov Disord. 2017;32(12):1701-9. https://doi.org/10.1002/mds. 27131.

15. Pahwa $\mathrm{R}$, Tanner CM, Hauser RA, Isaacson $\mathrm{SH}$, Nausieda PA, Truong DD, et al. ADS-5102 (amantadine) extended-release capsules for levodopa-induced dyskinesia in Parkinson disease (EASE LID study): a randomized clinical trial. JAMA Neurol. 2017;74(8):941-9. https://doi.org/10.1001/ jamaneurol.2017.0943.

16. Goetz CG, Nutt JG, Stebbins GT. The Unified Dyskinesia Rating Scale: presentation and clinimetric profile. Mov Disord. 2008;23(16):2398-403. https://doi.org/10.1002/mds.22341.

17. Elmer LW, Juncos JL, Singer C, Truong DD, Criswell SR, Parashos S, et al. Pooled analyses of phase III studies of ADS-5102 (amantadine) extended-release capsules for dyskinesia in Parkinson's disease. CNS Drugs. 2018;32(4):387-98. https://doi.org/10.1007/ s40263-018-0498-4.

18. Hauser RA, Friedlander J, Zesiewicz TA, Adler $\mathrm{CH}$, Seeberger LC, O'Brien CF, et al. A home diary to assess functional status in patients with Parkinson's disease with motor fluctuations and dyskinesia. Clin Neuropharmacol. 2000;23(2):75-81.

19. Folstein MF, Folstein SE, McHugh PR (1975) "Minimental state". A practical method for grading the cognitive state of patients for the clinician. J Psychiatr Res. 12(3):189-98.

20. Movement Disorder Society-Unified Parkinson's Disease Rating Scale Milwaukee, WI: Movement Disoder Society; 2019 https://www. movementdisorders.org/MDS-Files1/PDFs/RatingScales/MDS-UPDRS_English_FINAL_February2019. pdf.

21. Horvath K, Aschermann Z, Kovacs M, Makkos A, Harmat M, Janszky J, et al. Minimal clinically important differences for the experiences of daily living parts of movement disorder society-sponsored unified Parkinson's disease rating scale. Mov Disord. 2017;32(5):789-93. https://doi.org/10. 1002/mds.26960.

22. Tinazzi $M$, Del Vesco C, Fincati E, Ottaviani S, Smania N, Moretto G, et al. Pain and motor complications in Parkinson's disease. J Neurol Neurosurg Psychiatry. 2006;77(7):822-5. https://doi.org/ 10.1136/jnnp.2005.079053.

23. Aiyer R, Mehta N, Gungor S, Gulati A. A systematic review of NMDA receptor antagonists for treatment of neuropathic pain in clinical practice. Clin J Pain. 2018;34(5):450-67. https://doi.org/10.1097/AJP. 0000000000000547 .

24. Kreutzwiser D, Tawfic QA. Expanding role of NMDA receptor antagonists in the management of pain. CNS Drugs. 2019;33(4):347-74. https://doi.org/10. 1007/s40263-019-00618-2.

25. Simuni T, Caspell-Garcia C, Coffey CS, Weintraub D, Mollenhauer B, Lasch S, et al. Baseline prevalence and longitudinal evolution of non-motor symptoms in early Parkinson's disease: the PPMI cohort. J Neurol Neurosurg Psychiatry. 2018;89(1): 78-88. https://doi.org/10.1136/jnnp-2017-316213.

26. Santos-Garcia D, de Deus Fonticoba T, Suarez Castro E, Aneiros Diaz A, McAfee D, Catalan MJ, et al. Non-motor symptom burden is strongly correlated to motor complications in patients with Parkinson's disease. Eur J Neurol. 2020;27(7):1210-23. https://doi.org/10.1111/ene.14221. 